\title{
日本語翻訳タスクへの帰納論理プログラミングの適用
}

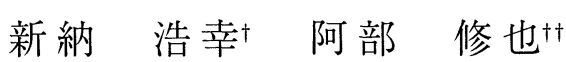

本論文では, SENSEVAL2 の日本語翻訳タスクに対して帰納論理プログラミング (Inductive Logic Programming, ILP) を適用する. 翻訳タスクは分類問題として定式 化できるため, 帰納学習の手法を利用して解決できる。しかし翻訳タスクは新たに訓 練デー夕を作るのが困難という特異なタスクになっており, 単純に確率統計的な帰納 学習手法を適用することはできない. Translation Memory の例文だけ，つまり少な い訓練データのみを用いて，どのように分類規則を学習すれば良いかが，翻訳タスク 解決の 1 つの鍵である。このために本論文では ILP を用いる. ILP は確率統計的な 㷌納学習手法にはない特徴を有する。それは背景知識を容易に利用可能である点であ る. 背景知識とは訓練データには明示されない問題固有の知識である。この背景知識 によって訓練データが少ない場合の学習が可能となる。ここではILP の実装システム として Progol, 背景知識として分類語彙表を利用することで, 翻訳タスクに対して正 解率 $54.0 \%$ を達成した。この值は, 付加的な訓練データを用いない SENSEVAL2 参 加の他システムと比較して優れている.

キーワード: 翻訳タスク, 帰納論理プログラミング, Progol, 分類語彙表, 背景知識

\section{Application of Inductive Logic Programming to Japanese Translation Task}

\author{
Hiroyuki Shinnou ${ }^{\dagger}$ and ShuYa $\mathrm{ABE}^{\dagger \dagger}$
}

In this paper, we apply Inductive Logic Programming (ILP) to Japanese Translation Task of SENSEVAL2. Translation Task is regarded as a classification problem, and can be solved by inductive learning methods. However, we cannot use general statistical learning methods for this task, because this task has the serious problem that it is hard to create training instances newly. Therefore, the problem is how to learn a classifier from instances in Translation Memory, that is, small training data. To overcome this problem, we use ILP which can handle background knowledge in learning. This is a big advantage over statistical learning methods. Background knowledge means domain specific knowledge which are not described in training data clearly. Using background knowledge, we can learn rules through small training data. In this paper, we used Progol as a ILP system, and 'bunrui-goi-hyou' as background knowledge to achieve the precision $54.0 \%$ for Translation Task. This precision is superior to other systems in the contest which did not create new training instances.

KeyWords: Translation Task, Inductive Logic Programming, Progol, thesaurus, background knowledge

†茨城大学工学部システム工学科, Department of Systems Engineering, Ibaraki University

†十 茨城大学大学院理工学研究科システム工学専攻, Graduate School of Scinence and Engineering, Ibaraki University (2003 年 4 月より株式会社システム計画研究所) 


\section{1 はじめに}

本論文では, SENSEVAL2 の日本語翻訳タスクに対して帰納論理プログラミング (Inductive Logic Programing, 以下 ILP と略す）を適用する. 背景知識として分類語彙表を利用すること で, 正解率 $54.0 \%$ を達成した。この值は, 訓練データを新たに作成しない翻訳夕スク参加の他 システムと比較して優れている.

SENSEVAL2 の日本語翻訳タスクは, Translation Memory（以下 TM と略す）と呼ばれる 日英対訳対が与えられ，テスト文中の該当単語を英訳する際に利用できる TM の例文番号を返 すタスクである1(黒橋, 白井 2001). これは英訳を語義と考えた場合の多義語の曖昧性解消問 題となっており, 分類問題の一種である.このため従来から活発に研究されている帰納学習手 法を用いて解決可能である。おそらく大規模かつ高品質な訓練デー夕を用いたシステムが，コ ンテストで優秀な成績を納めるはずである.

しかし翻訳タスクでは大規模かつ高品質な訓練データを用意するコストが高い. TM は $1 つ$ の単語に対して平均して 21.6 例文がある. 今仮にある単語 $\mathrm{A}$ の例文として $i d_{1}$ から $i d_{20}$ まで の 20 例文が TM に記載されているとする，新たに訓練デー夕を作成する場合，単語 $\mathrm{A}$ を含む 新たな文を持ってきて, $i d_{1}$ から $i d_{20}$ のどれか 1 つのラベルをその事例に与える必要がある. ○か×かの二者択一は比較的容易であるが, 20 個のラベルの中から最も適切な 1 つを選ぶのは 非常に負荷のかかる作業である。この理由のために, 実際のコンテストにおいて, 大規模かつ高 品質な訓練デー夕を用意する方法をとったシステムは 1 つ（ Ibaraki）だけであった.ここで は訓練データを新たに作成せずに，日本語翻訳タスクを解決することを目標とする。訓練デー 夕を新たに作成しないとしても，TM の例文は訓練データとして扱える，ただし TM の例文を 訓練デー夕と見た場合，その量は少量と言わざるをえない。つまり問題は，少量の訓練デー夕 からどのようにして精度の高い分類規則を獲得するかである。そのための戦略として ILPを用 いる.

少量の訓練データからどのようして分類規則を学習したらよいかは, 機械学習における $1 つ$ の重要な課題である. その解決方法として背景知識の利用が提案されている (秋葉, アルモアリ 厶, 金田 1998). 背景知識とは, 訓練デー夕には明示されない問題固有の知識であり, 広く捉え れば，人間の持つ常識的知識と考えて良い.一種の知識データベースである. 問題はその背景 知識を，どのように学習手法に取り入れてゆくかである．その解決のために提案されているの が ILP である. ILP は訓練デー夕を述語論理の形式で表し，そこから分類規則に相当する規則 （述語論理の形式では節に対応）を導出する．知識データベースは述語論理の形式によって自然 に表現できるので，背景知識の利用の観点からはILP を用いた学習戦略が優れている(古川， 尾崎, 植野 2001). 更に ILP の背景知識では, 複雑なグラフ構造を持ったものも表現できるの で，近年， CMU の機械学習チームはWeb ページの文書分類にILP を利用している (Craven,

1 厳密には, 英訳自体を解答としてもよいが, ここではこの解答形式は考慮しない. 
DiPasquo, Freitag, McCallum, Mitchell, Nigam and Slattery 2000). 更にいくつかの自然言語 処理への応用も知られている (Cohen 1995)(Califf and Mooney 1997)(嶋津, 古川 2000).

本論文では, ILP の処理系として Muggleton による Progol を利用する (Muggleton 1995). Progol によって多義語の曖昧性解消を行う.そして背景知識としては分類語彙表 (国立国語研 究所 1994) を利用する. 以下 2 章で多義語の曖昧性解消を ILP で行う方法を示す. 3 章では分 類語彙表をどのように背景知識として組み込むかを説明し，4 章で実験， 5 章で考察を述べ, 最 後にまとめる.

\section{ILP による多義語の曖昧性解消}

ILP による分類問題の解決については，書籍 (古川他 2001) に詳しく解説されている.ここ では関連する事柄についてのポイントのみを述べる.

自然言語処理の個々の問題の多くは分類問題として以下のように定式化できる．まず分類先 のクラスの集合 $C=\left\{c_{1}, c_{2}, \cdots, c_{m}\right\}$ を設定し, 次に事例 $x$ を $n$ 個の要素からなる素性べクトル $\left(f_{1}, f_{1}, \cdots, f_{n}\right)$ で表す. 各素性は事例を識別するための観点に対応する. $k$ 番目の素性を $a t t r_{k}$ と名前をつけておく. 訓練事例は事例 $x$ とそのクラス $c_{x}$ の対の情報 $\left(x, c_{x}\right)$ であり, これを多 数集めたものが訓練データとなる. 確率統計的な帰納学習手法（決定木, 決定リスト, ME 法 など）は訓練デー夕を入力として, 分類器 $F$ を構築する. 分類器 $F$ への入力は事例であり, 出 力はクラスである. 分類問題を解決するとは，この分類器 $F$ を作成することである.

ILP では訓練事例 $\left(x, c_{x}\right)$ を以下の節で表現する.

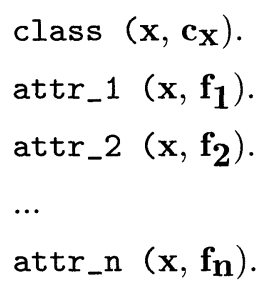

これらの節が訓練データとなるＩLP ではここからあるクラスにのみ共通して見られ，他の クラスには見られないある種のパターンの発見を行う.これは本質的に帰納推論の処理である. その結果，例えば，以下のような節を ILPは出力する.

$$
\operatorname{class}(X, c):-\operatorname{attr} \_5(X, h) \text {. }
$$

これは事例 $\mathrm{X}$ の 5 番目の素性が $\mathrm{h}$ であれば, 事例 $\mathrm{X}$ のクラスが c であることを示して

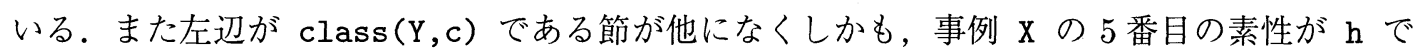
なければ, 事例 $\mathrm{X}$ のクラスは c でないことも示している. 
ここまでは特に確率統計的な手法と大きな違いはない。確率統計的手法にはないILP の大 きな特徵は，訓練データ中に任意の述語や節を記述できる点である。この与えられた訓練事例 の集合以外から追加される述語や節を背景知識と呼ぶ。つまり問題固有の知識や, 人間の常識 といったものを背景知識として訓練デー夕内に簡単に追加できることが ILP の大きな特徵と なっている，特に，述語論理の節の表現力は高く, ILP は表形式（素性べクトル）では表現で きない複雑な構造を持つ訓練事例も表現できる。

以下，ILPによって多義語の曖昧性解消を行う．利用する素性は以下の 4 種類を用いた.
対象単語の直前の単語 $\mathrm{e} 1$
対象単語の直後の単語 $\mathrm{e} 2$
e1 から前方 3 単語 $e 3$
e2 から後方 3 単語 e4

例を示す. 対象とする多義語を「与える」として「彼では力不足という印象を与えるかもし れない。という文は, 以下のように形態素解析される. 第 1 列が表記, 第 2 列が原型, 第 3 列 が品詞を表す.

$\begin{array}{lll}\text { 彼 } & \text { 彼 } & \text { 普通名詞 } \\ \text { で } & \text { で } & \text { 格助詞 } \\ \text { は } & \text { は } & \text { 副助詞 } \\ \text { 力 } & \text { 力 } & \text { 普通名詞 } \\ \text { 不足 } & \text { 不足 } & \text { サ変名詞 } \\ \text { と } & \text { と } & \text { 格助詞 } \\ \text { いう } & \text { いう } & \text { 動詞 } \\ \text { 印象 } & \text { 印象 } & \text { 普通名詞 } \\ \text { を } & \text { を } & \text { 格助詞 } \\ \text { 与える } & \text { 与える } & \text { 動詞 } \\ \text { かも } & \text { かも } & \text { 接続助詞 } \\ \text { しれ } & \text { しれる } & \text { 動詞 } \\ \text { ない } & \text { ない } & \text { 形容詞性述語接 } \\ \text { 。 } & \text { 。 } & \text { 句点 }\end{array}$

ここから以下の素性が得られる.

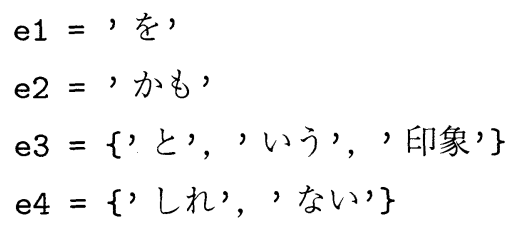


例えば，この例文の ID が sen25 であり，この文の「与える」の語義 ID が ataeru2 だ とすれば，この例文に対するデータは，以下の節で表現される.

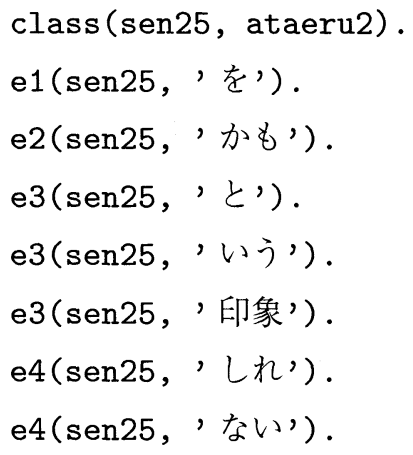

\section{3 分類語彙表の利用}

前節の設定で，訓練事例を節に変換すれば，ILPにより分類規則が節の形で得られる。ここ で得られる規則を，背景知識を利用することで更に高めることも可能である.

本論文では，背景知識として分類語彙表 (国立国語研究所 1994)を利用する．分類語彙表は 木構造をもったシソーラスである。ただし木のリーフノードにのみ単語が配置されている。つ まり木のあるノード以下に位置するリーフノードの単語群はそのノードの階層において同一の 意味クラスに属すると考えて良い，当然階層が上がるほど，同じ意味クラスの単語は増加する ことになる。

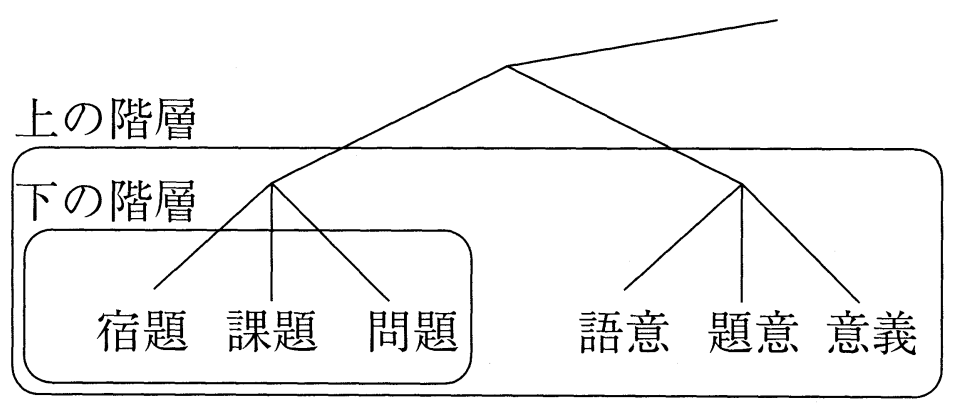

図 1 分類語彙表

例えば図 1 において一番下の階層で考えると,「課題」「宿題」「問題」は同じ意味をもつグ ループとなり，「語意」「題意」「意義」は別の意味のグループとなる１つ上の階層で考えると， これらの単語はすべて同じ意味をもつ単語と見なせる，本論では一番下の階層でみた場合のグ 
ループの単語を同じ意味をもつ単語とした.

図 2 に示した規則は，素性 (e1, e2, e3, e4 の単語) と，分類語彙表に含まれる単語と，そ の単語と同じ意味を持つ単語を結び付ける。つまり, ILP は同じ意味の単語を同じ単語として 扱うようになる。述語b は, 分類語彙表の単語とその意味の番号の組を表す. 述語 e1 $\sim$ e4 は, 文の素性を表す。述語 e1_w e4_w は, 単語の代わりに語義を用いることによって述語 e1 〜 e4 を拡張したものであり, e1〜 e4の代りに素性として用いられる.

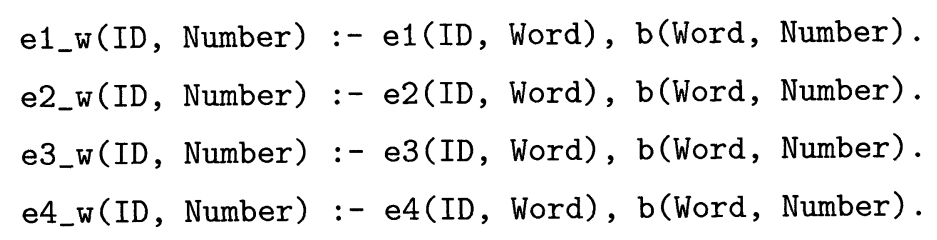

図 2 単語を語義に一般化する規則

\section{4 実験}

本論文では ILP の実装システムとして Muggleton による Progol(Muggleton 1995) を利用 した. Progol への入力形式は, Prolog 形式の述語や節であり, 本論文で説明に用いた形式で行 える.ILP の実装システムは他にも存在するが, Progol が最もよく利用される代表的なシステ ムである。

まず，TM の形態素解析結果から素性（e1，e2，e3，e4）を抽出する．また例文番号を分 類先のクラスとする。例文番号, クラス, 素性の情報を節に変換し, Progol の入力ファイルを 作成する，入力ファイルを Progol に読み込ませて，規則を生成した，テストは翻訳タスクの コンテストで用いられた全 40 単語（各単語 30 問，計 1,200 問）が対象である.それらに対し て, Progolにより得られた規則を使い, 多義語の曖昧性解消のテストを行った（実験 1）。次に， TM の例文の他に背景知識として分類語彙表を用いて，Progolにより規則を生成した。得られ た規則を使い，40 単語に対してテストを行った（実験 2 ）. 実験 1 と実験 2 の結果を表 1 に示 す. 表 1 の TM の列は実験 1 の結果を示し, TM+背景知識の列は実験 2 の結果を示している. 平均の正解率は TM のみは $48.7 \%$ であり, TM+背景知識 では $54.0 \%$ であった. 分類語彙 表を背景知識として用いた効果が確認できる。 またこの $54.0 \%$ という值は, 付加的な訓練デー 夕を用いない翻訳タスクの他のシステムの正解率と比較しても, 優秀な值と言える.

次に確率統計的な手法の 1 つである決定リストと比較してみる. 論文 (新納 2001) では翻訳 タスクの正解から語義（例文番号）をグループ化して，TM の例文番号をグループ化すること で，正解率が向上することを述べている．そのため翻訳タスクに対する学習手法を比較する場 
表 1 背景知識の効果

\begin{tabular}{|c|c|c||c|c|c|}
\hline 見出 & TM & TM+背景知識 & $\downarrow$ & $\downarrow$ & $\downarrow$ \\
\hline ataeru & 0.167 & 0.167 & kiroku & 0.267 & 0.267 \\
baai & 0.033 & 0.033 & koeru & 0.967 & 0.867 \\
chikaku & 0.333 & 0.500 & kokunai & 1.000 & 1.000 \\
chushin & 0.367 & 0.367 & kotoba & 0.700 & 0.933 \\
deru & 0.333 & 0.333 & mae & 0.167 & 0.000 \\
egaku & 0.333 & 0.333 & mamoru & 0.033 & 0.033 \\
hakaru & 0.600 & 0.567 & matsu & 0.867 & 0.867 \\
hana & 0.667 & 0.700 & miseru & 0.733 & 0.933 \\
hantai & 0.800 & 0.933 & mitomeru & 0.233 & 0.233 \\
ima & 0.067 & 0.867 & mondai & 0.533 & 0.533 \\
imi & 0.400 & 0.567 & motomeru & 0.867 & 0.867 \\
ippan & 0.333 & 0.533 & motsu & 0.333 & 0.867 \\
ippou & 0.633 & 0.533 & mune & 0.233 & 0.267 \\
iu & 0.033 & 0.033 & noru & 0.300 & 0.267 \\
jidai & 0.700 & 0.733 & shimin & 0.867 & 0.967 \\
jigyou & 0.500 & 0.500 & sugata & 0.200 & 0.133 \\
kaku_n & 0.800 & 0.733 & tsukau & 0.700 & 0.667 \\
kaku_v & 0.967 & 0.967 & tsukuru & 0.633 & 0.367 \\
kau & 0.467 & 0.833 & tsutaeru & 0.400 & 0.367 \\
kiku & 0.500 & 0.500 & ukeru & 0.400 & 0.433 \\
\hline$\downarrow$ & $\downarrow$ & $\downarrow$ & 平均 & 0.487 & 0.540 \\
\hline
\end{tabular}

合，TM の例文のグループ化を揃える必要がある，そこで，ここでは論文 (新納 2001) と同じ手 法を用いて，正解データから例文をクラスタリングし，同一の訓練データを用いることにした． 確率統計的な学習手法としては，決定リストを用いた（実験 3 ）。実験の結果を表 2 に示す.

平均の正解率は決定リストでは $54.8 \%$ であったが，本手法では $60.5 \%$ の結果を得た。つま

り TM だけを用いた学習システムとしては，決定リストよりも ILP の方が優れていた.

ただし，いくつかの単語については，実験 3 での ILP の正解率が，実験 1 での ILP の正 解率や，実験 3 での決定リストの正解率よりも，極端に低くなっている．例えば， mokuteki， jidai, ukeru, baai, egaku, ima などである.これらの正解率が極端に下がっている理由は, 学 習結果として生成された節の順序の問題である。これは, default 規則にあたるものを適切に設 定できなかったことを意味している。これについては次節の考察に記述する.

\section{5 考察}

背景知識を用いても必ずしも正解率が高くなるとは限らないことは容易に予想がつく．実際 に，実験 $1 ， 2$ でも精度が下がる単語がいくつか存在する．また，実験 3 と同様の課題について さらに分類語彙表を背景知識として用いた実験も行ったが，この場合の平均の正解率も $60.5 \%$ から $58.9 \%$ に低下した．分類語彙表を用いることで，単語を語義に一般化すれば，ある部分で 
表 2 決定リストとの比較

\begin{tabular}{|c|c|c||c|c|c|}
\hline 見出し & 決定リスト & ILP & $\downarrow$ & $\downarrow$ & $\downarrow$ \\
\hline ataeru & 0.333 & 0.867 & kiroku & 0.833 & 0.933 \\
baai & 0.367 & 0.933 & koeru & 0.633 & 0.600 \\
chikaku & 0.367 & 0.467 & kokunai & 1.000 & 0.633 \\
chushin & 0.200 & 0.700 & kotoba & 0.967 & 0.967 \\
deru & 0.367 & 0.233 & mae & 0.267 & 0.200 \\
egaku & 0.567 & 0.267 & mamoru & 0.367 & 0.833 \\
hakaru & 0.733 & 0.900 & matsu & 0.867 & 0.767 \\
hana & 0.800 & 0.933 & miseru & 0.933 & 0.733 \\
hantai & 0.900 & 0.967 & mitomeru & 0.200 & 0.300 \\
ima & 0.367 & 0.933 & mondai & 0.533 & 0.467 \\
imi & 0.767 & 1.000 & motomeru & 0.633 & 0.000 \\
ippan & 0.333 & 0.567 & motsu & 0.900 & 0.833 \\
ippou & 0.500 & 0.767 & mune & 0.267 & 0.300 \\
iu & 0.733 & 0.900 & noru & 0.300 & 0.433 \\
jidai & 0.567 & 0.233 & shimin & 0.567 & 0.433 \\
jigyou & 0.667 & 0.567 & sugata & 0.367 & 0.233 \\
kaku_n & 0.300 & 0.800 & tsukau & 0.533 & 0.967 \\
kaku_v & 0.967 & 0.967 & tsukuru & 0.033 & 0.233 \\
kau & 0.733 & 0.533 & tsutaeru & 0.367 & 0.200 \\
kiku & 0.467 & 0.500 & ukeru & 0.333 & 0.100 \\
\hline$\downarrow$ & $\downarrow$ & $\downarrow$ & 平均 & 0.548 & 0.605 \\
\hline
\end{tabular}

は効果があるが，別の部分では過度の一般化になるので，その影響が現れると精度は下がる。 過度の一般化への対処は今後の課題である.

また節を規則として見た場合，節の適用順序が重要になる。これは入力事例と訓練事例に矛 盾がないことを仮定する論理を基盤とする推論では問題にならない.しかし現実の問題では訓 練デー夕に矛盾する入力も有り得る。例えば，以下のケースを考えてみる.

$$
\begin{aligned}
& \operatorname{class}(\mathrm{X}, \mathrm{c} 1):-\operatorname{attr} 1(\mathrm{X}, \mathrm{a}) . \quad \% \% \text { 節 } \mathrm{A} \\
& \mathrm{class}(\mathrm{X}, \mathrm{c} 2):-\operatorname{attr} 2(\mathrm{X}, \mathrm{b}) . \quad \% \% \text { 節 } \mathrm{B}
\end{aligned}
$$

節 $\mathrm{A}$ は事例の 1 番目の素性の值が $\mathrm{a}$ なら分類クラスが $\mathrm{c} 1$ であることを示し，節 $\mathrm{B}$ は事例 の 2 番目の素性の值が $\mathrm{b}$ なら分類クラスが $\mathrm{c} 2$ であることを示している. この 2 つの規則が学 習されたということは, 訓練デー夕内には, 1 番目の素性の值が a でしかも 2 番目の素性の值 が $\mathrm{b}$ の事例が存在しなかったことを意味する。また同時にそのような事例が存在しないことも 仮定したことになる．ところが，現実にはそのような事例が入力されることもある。この場合， 上記の規則では，クラスは $\mathrm{c} 1$ と識別される。一方，上記の規則の順序を変更し，以下の形にす れば，クラスは $\mathrm{c} 2$ と識別される.

$$
\begin{aligned}
& \operatorname{class}(X, c 2):-\operatorname{attr} 2(X, b) . \quad \% \% \text { 節 B } \\
& \operatorname{class}(X, c 1):-\operatorname{attr} 1(X, a) . \quad \% \% \text { 節 A }
\end{aligned}
$$


節の出現順序は Progol では考慮されていないようである. 訓練データに対応する述語や節 の与える順序が，生成される節の順序に影響する。本実験ではこの点は何も対策をたてずに， 学習された節をそのまま適用した。しかしこのような節の順序は default 規則が何に対応する かという問題にもなっており，正解率に大きく影響する．実験 3 で正解率が大きく下がる単語 は，みなこの問題がからんでいた。この対策も今後の課題である.

また上記の問題とも関連するが ILP では頻度の情報がなくなってしまう．例えば，上記の 節 B に合致した訓練事例の数が 10,000 で，節 A に合致した訓練事例の数が 1 のとき，普通に 考えれば合致する事例数の多い節 $\mathrm{B}$ を優先させるのが正しいであろう．しかし ILP では，頻 度の情報が節 B と節 $\mathrm{A}$ に反映されず，結果として同じ重みを与えている形になる。この問題 は，確率と論理を結び付ける研究と関連しており，いまだ決定版は出ていない状況である(古川 他 2001).

少量の訓練データしかない場合, 識別精度を高めるには, 訓練データ以外の情報，つまり 背景知識をいかに取り込むかが重要である．今回の実験では背景知識として分類語彙表を用い たが，単語を語義で一般化することは通常の確率統計的な手法でも実現可能であり (Aluallim， Akiba, Yamazaki and Kaneda 1994)，この点では ILP を用いた利点は少ない.ただ翻訳タス クでは背景知識の利用という観点以外からも，ILP を用いた方が適切であると思われる。なぜ ならここで扱っている少量のデー夕は統計学でいうサンプルではないからである，例えば，仮に

語義 c1 の例文 1 から e1=a と e2=b いう素性

語義 c2 の例文 2 から e1=c と e2=d いう素性

語義 c1 の例文 3 から e1=a と e2=e いう素性

が得られたとする．確率統計的な手法では，以下の 5 つの確率が高くなる.

$\begin{array}{ll}\text { 確率 } & \text { 対応する例文 } \\ P(c 1 \mid e 1=a) & \text { 例文 1, 例文 } 3 \\ P(c 1 \mid e 2=b) & \text { 例文 } 1 \\ P(c 1 \mid e 2=e) & \text { 例文 } 3 \\ P(c 2 \mid e 1=c) & \text { 例文 } 2 \\ P(c 2 \mid e 2=d) & \text { 例文 } 2\end{array}$

そして特に $\mathrm{P}(\mathrm{c} 1 \mid \mathrm{e} 1=\mathrm{a})$ の確率が高くなる. 同じクラス $\mathrm{c} 1$ の例文 1 と 3 に素性 $\mathrm{e} 1=\mathrm{a}$ が発生 
しているからである。ただし，このような確率の算出が妥当なのは，例文 $1 ， 2 ， 3$ がサンプル， つまり等確率で現れる事例という仮定がある。TM の例文はサンプルではありえない. 例えば, ある単語は $90 \%$ 以上の割合で, 語義 $\mathrm{c} 1$ の意味用法で利用されるとしても, TM のその単語の 例文の $90 \%$ 以上が語義 $\mathrm{c} 1$ の例文であることはない.つまり，TM の例文数から素性に重みを つけるのは意味がない，そのため TM から得られる素性は，同じ重みで評価するのが妥当であ ろう。今回 ILP が決定リストよりも優れた結果を出せた要因がそこにあると思われる.

また ILP の背景知識として，今回は分類語彙表を用いたが，任意の節が組み込めることは 大きな魅力である。特に, Web ページは解析の観点によっては, 複雑な構造をもつことになり, そのような複雑なデー夕構造からの学習には ILP が利用できるため, 今後応用範囲が広がる研 究分野だと思われる.

\section{6 おわりに}

本論文では，SENSEVAL2 の日本語翻訳タスクに対して ILP を適用した。ILP は背景知識 を容易に学習に組み込めるという確率統計的な手法にはない長所がある. 翻訳夕スクは少量の 訓練データしか利用できない分類問題と見なせるため, 翻訳タスクは ILP の格好の応用となっ ている。ここでは ILP の実装システムとして Progol, 背景知識として分類語彙表を利用するこ とで, 正解率 $54.0 \%$ を達成した。この值は, 訓練デー夕を新たに作成しない翻訳タスクの他シ ステムと比較して優れている。また語義のクラスを同一にした訓練データを用いて, 確率統計 的手法の 1 つである決定リストと比較したところ, 決定リストの正解率 $54.8 \%$ に対して, ILP では $60.5 \%$ となり，決定リストよりも良い結果が得られた。

分類語彙表を利用した場合の過度の一般化をどう押さえるか, 出力される規則の優先順序を どのように制御するかが今後の課題である.

\section{参考文献}

秋葉泰弘，フセイン・アルモアリム，金田重郎 (1998). “例からの学習技術の応用にむけて, 2. 応用上の課題に対する解決法.”情報処理, 39 (3), pp. 245-251.

Hussein Aluallim, Yasuhiro Akiba, Takefumi Yamazaki, Shigeo Kaneda (1994). "Induction of Japanese-English Translation Rules from Ambiguous Examples and a Large Semantic Hierarchy." 人工知能学会誌, 9 (5), pp. 730-740.

Mary Elaine Califf, Raymond J. Mooney (1997). "Relational Learning of Pattern-Match Rules for Information Extraction." In Working Notes of AAAI Spring Symposium on Applying Machine Learning to Discourse Processing, pp. 6-11. 
William Cohen (1995). "Learning to Classify English Text with ILP method." In Proceedings of the 5th International Workshop on Inductive Logic Programming, pp. 3-24.

Mark Craven, Dan DiPasquo, Dayne Freitag, Andrew McCallum, Tom Mitchell, Kamal Nigam, Sean Slattery (2000). "Learning to Constrcut Knowledge Bases from the World

Wide Web." Artificial Intelligence, 118 (1-2), pp. 69-113.

古川康一, 尾崎知伸, 植野研 (2001). 㷌納論理プログラミング. 共立出版.

国立国語研究所 (1994). 分類語彙表. 秀英出版.

黒橋禎夫, 白井清昭 (2001). “SENSEVAL-2 日本語夕スク.”電子情報通信学会言語とコミュニ ケーション研究会, NLC-36〜48, pp. 1-8.

Stephen Muggleton (1995). "Inverse Entailment and Progol." New Generation Computing, Special issue on Inductive Logic Programming, 13 (3-4), pp. 245-286.

嶋津恵子, 古川康一 (2000). “データベースからの知識発見システム DM-Amp - 設計と実装と エキスパートシステム開発への応用.”人工知能学会誌, 15 (4), pp. 629-637.

新納浩幸 (2001). “SENSEVAL2 日本語翻訳タスクに向けて作成した語義判別学習システム

Ibaraki.”電子情報通信学会言語とコミュニケーション研究会, NLC-36〜48, pp. 25-30.

\section{略歴}

新納 浩幸: 1985 年東京工業大学理学部情報科学科卒業. 1987 年同大学大学院 理工学研究科情報科学専攻修士課程修了. 同年富士ゼロックス, 翌年松下電 器を経て, 1993 年茨城大学工学部システム工学科助手. 1997 年同学科講師, 2001 年同学科助教授. 情報処理学会, 人工知能学会, 言語処理学会, ACL 各会員. 博士 (工学).

阿部 修也： 2001 年茨城大学工学部システム工学科卒業. 2003 年茨城大学大学 院理工学研究科システム工学専攻博士前期課程修了. 同年 4 月より株式会社 システム計画研究所. 